\title{
Time series analyses reveal transient relationships between abundance of larval anchovy and environmental variables in the coastal waters southwest of Taiwan
}

\author{
CHIH-HAO HSIEH, ${ }^{1}$ CHIH-SHIN CHEN, ${ }^{2}$ \\ TAI-SHENG CHIU, ${ }^{3}$ KUO-TIEN LEE, ${ }^{4}$ \\ FENG-JEN SHIEH, ${ }^{4}$ JIA-YI PAN ${ }^{5}$ AND \\ MING-AN LEE ${ }^{4} *$ \\ ${ }^{1}$ Institute of Oceanography, National Taiwan University, 1 \\ Roosevelt Rd., Sec. 4, Taipei 10617, Taiwan \\ ${ }^{2}$ Institute of Marine Affairs and Resource Management, National \\ Taiwan Ocean University, 2 Pei-Ning Rd., Keelung 20224, \\ Taiwan \\ ${ }^{3}$ Institute of Zoology, College of Life Science, National Taiwan \\ University, 1 Roosevelt Rd., Sec. 4, Taipei 10617, Taiwan \\ ${ }^{4}$ Department of Environmental Biology and Fisheries Science, \\ National Taiwan Ocean University, 2 Pei-Ning Rd., Keelung \\ 20224, Taiwan \\ ${ }^{5}$ Marine Fisheries Division, Fishery Research Institute, 199 \\ Hou-Ih Rd., Keelung 20246, Taiwan
}

\begin{abstract}
We investigated environmental effects on larval anchovy fluctuations (based on CPUE from 1980 to 2000) in the waters off southwestern Taiwan using advanced time series analyses, including the statespace approach to remove seasonality, wavelet analysis to investigate transient relationships, and stationary bootstrap to test correlation between time series. For large-scale environmental effects, we used the Southern Oscillation Index (SOI) to represent the El Niño Southern Oscillation (ENSO); for local hydrographic conditions, we used sea surface temperature (SST), river runoff, and mixing conditions. Whereas the anchovy catch consisted of a northern species (Engraulis japonicus) and two southern species (Encrasicholina heteroloba and Encrasicholina punctifer), the magnitude of the anchovy catch appeared to be mainly determined by the strength of Eng. japonicus (Japanese anchovy). The main factor that caused the interannual variation of anchovy CPUE might change through time. The CPUE showed a negative correla-
\end{abstract}

*Correspondence. e-mail: malee@ntou.edu.tw

Received 3 December 2007

Revised version accepted 19 September 2008 tion with combination of water temperature and river runoff before 1987 and a positive correlation with river runoff after 1988. Whereas a significant negative correlation between CPUE and ENSOs existed, this correlation was driven completely by the lowfrequency ENSO events and explained only 10\% of the variance. Several previous studies on this population emphasized that the fluctuations of larval anchovy abundance were determined by local SST. Our analyses indicated that such a correlation was transient and simply reflected ENSO signals. Recent advances in physical oceanography around Taiwan showed that the ENSOs reduced the strength of the Asian monsoon and thus weakened the China Coastal Current toward Taiwan. The decline of larval anchovy during ENSO may be due to reduced China Coastal Current, which is important in facilitating the spawning migration of the Japanese anchovy.

Key words: El Niño Southern Oscillation, hydrographic conditions, multivariate moving-window regression, seasonal adjustments, stationary bootstrap, wavelet analysis

\section{INTRODUCTION}

Accumulating evidence indicates that environmental variations have profound effects on marine fish populations (Mantua et al., 1997; Benson and Trites, 2002). Notably, large-scale fluctuations of sardine and anchovy populations in relation to environmental changes and fishing effects have attracted global attention because these fisheries have great economic value and far-reaching societal impacts (Jacobson et al., 2001). As fishing and the environment may play important roles in determining fish stock size, understanding the environmental effects is indispensable for fisheries management (Jacobson et al., 2001). Indeed, understanding the environmental effects on fish populations is an essential step toward ecosystembased management of fisheries that is increasingly becoming a standard requirement in management policy (Pikitch et al., 2004). 
Time series analyses are valuable tools for investigating long-term fluctuations of fish populations and relationships between the populations and environmental variables; for example, the state-space method to impute missing data and remove seasonal trends (Durbin and Koopman, 2001), the nonparametric stationary bootstrap method for correlation and regression analyses of autocorrelated time series (Politis and Romano, 1994), and wavelet analysis on non-stationary relationships between biological and environmental variables (Torrence and Compo, 1998). These recently developed tools, while used widely in economic and geophysical literature, are less familiar to ecologists. These methods may be superior to traditional approaches such as the ARIMA model and spectral analysis, which may produce spurious relationships due to the assumption of stationarity in the time series. Here, we use 21-yr monthly time series data of larval anchovy and environmental variables as a case study to show the efficacy of these tools. We point readers to free available statistical software that can be easily implemented for those analyses.

The anchovy fishery (targeting the larvae) is one of the most important commercial fisheries in the coastal waters of Taiwan of the western North Pacific (Tsai et al., 1997). Since the 1980s, catch records based on the same fishing practice have been collected by fisheries associations, which can potentially provide useful data for investigating questions of global fluctuations of anchovy populations. Two main anchovy fishing grounds exist around Taiwan: the coastal waters off northeastern (I-lan) and southwestern (Fangliao) Taiwan (Chiu et al., 1997). The anchovy catches around Taiwan consist mainly of one northern species (Engraulis japonicus) and two southern species (Encrasicholina heteroloba and Encrasicholina punctifer) (Chiu et al., 1997; Tsai et al., 1997). Because it is impractical to separate and sort larvae in the catch, these three species are not segregated in the landing data. These three species migrate toward Taiwan and spawn around the coastal waters, and their larvae later become the target of the anchovy fishery (Chen and Chiu, 2003). The larvae that survive fishing and natural mortality then undertake a feeding migration away from Taiwan (Chen and Chiu, 2003). The exact migration routes of anchovy populations in the western North Pacific are not known at this time.

Ecological studies of anchovy populations around Taiwan based on fishery-independent data are relatively few. Notable exceptions are detailed age-growth studies and genetic population studies of the northern species (Japanese anchovy). According to microsatellite DNA analysis, two distinct populations of
Japanese anchovy were found in the coastal waters around Taiwan: a northeastern stock and southwestern stock (Yu et al., 2002). The northeastern stock is composed of two seasonal cohorts, spring and autumn, with different demographic parameters (Chiu and Chen, 2001; Chen and Chiu, 2003); nonetheless, these two seasonal cohorts belong to a single population (Yu et al., 2002). Studies on the southern species are even scarcer. The only study on one of the southern species (Enc. punctifer) indicated that this species arrives near the coast of northern Taiwan between October and March (Wang and Tzeng, 1999).

Although our understanding of the basic ecology of the anchovy populations around Taiwan is limited, herein we attempt to investigate environmental effects on variation in the anchovy population size using fisheries catch-effort data. We examined local environmental variables that have been shown to affect anchovy populations (Lee et al., 1995; Tsai et al., 1997; Hsia et al., 1998, 2004; Lloret et al., 2004). We focused on the southwestern stock for which parallel environmental data were available (Fig. 1). Tsai et al. (1997) analyzed data from 1980 to 1992 and concluded that the fluctuations in anchovy populations in waters of southwestern Taiwan were correlated with local water temperature, which in turn were related to the Southern Oscillation Index (SOI). At that time, however, the species composition of the anchovy fishery was not available and the ocean circulation patterns around Taiwan were not well understood. Moreover, they used the ARIMA model and spectral analysis and assumed a stationary relationship between larval anchovy abundance and environmental variables. In this study, we investigated this issue with updated time series data (1980-2000), knowledge of the ocean circulation, information on the species composition, and new analytical approaches.

Our purposes are to examine the long-term trends and variability of larval anchovy populations in response to environmental changes. Specifically, we examine the effect of the global climate index, SOI, which represents the El NiñoSouthern Oscillation (ENSO) condition, and three local hydrographic variables: water temperature, river runoff, and wind mixing conditions. Water temperature has been proposed to be important in determining egg development and larval survival of anchovy (Tsai et al., 1997; Takasuka et al., 2007). River runoff is assumed to be indicative of the nutrient condition that is linked to food availability in the habitat of the anchovy (Tsai et al., 1997). Wind mixing may have positive effects by bringing in nutrients (Lloret et al., 2004) or negative effects by creating a turbulent environment that 


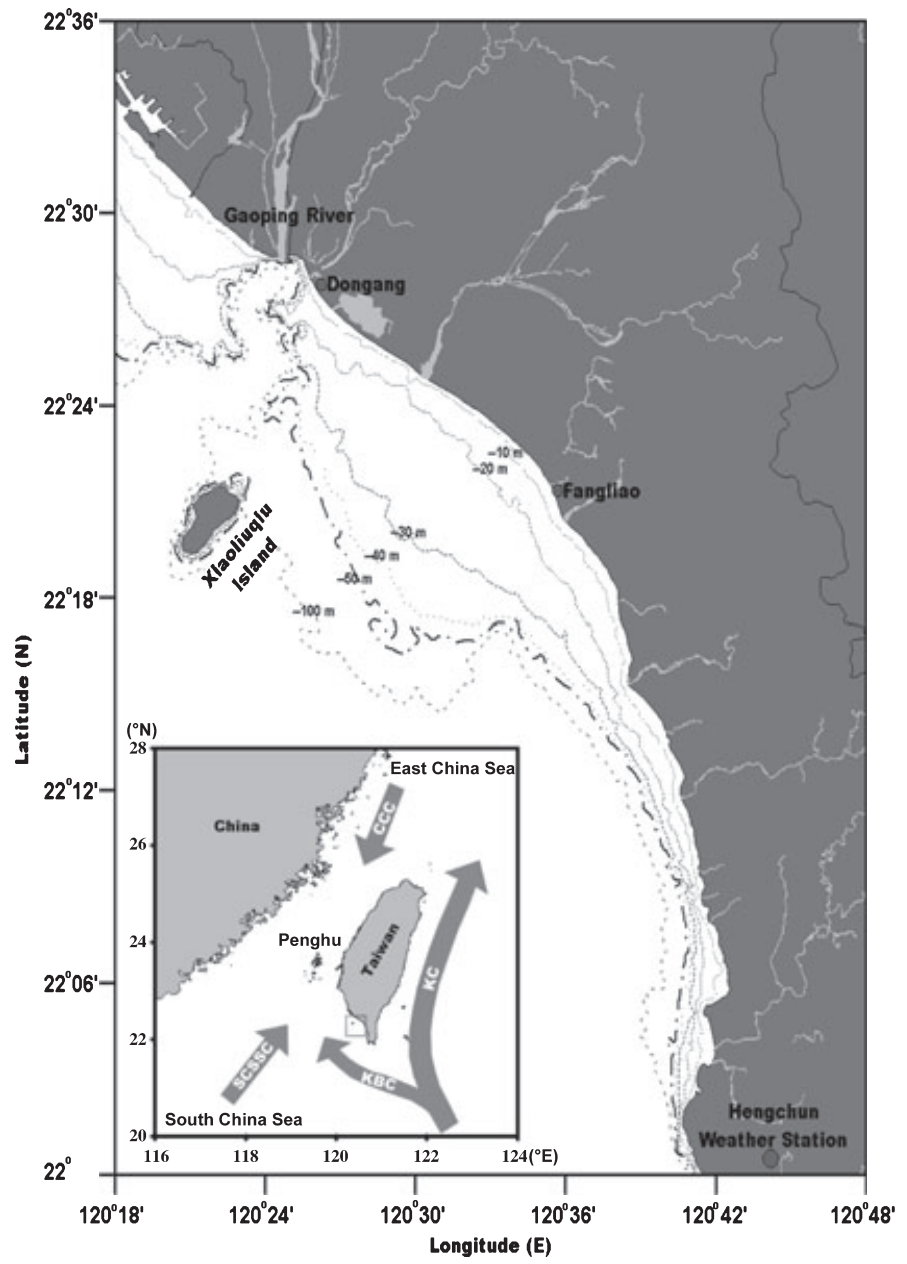

Figure 1. Map showing the study area (fishing ground of larval anchovy). Arrows indicate the main currents around Taiwan: KC, Kuroshio Current; KBC, Kuroshio Branch Current; CCC, China Coastal Current; SCSSC, South China Sea Surface Current. reduces feeding efficiency of anchovy larvae or advects them away from suitable habitats (Wroblewski and Richman, 1987). The information gained herein may be useful for designing management strategies for the anchovy fishery in the waters off southwestern Taiwan.

\section{MATERIALS AND METHODS}

\section{Data}

The larval anchovy fishery is operated in the coastal waters off Fangliao, southwestern Taiwan (Fig. 1). The catch and effort data for the larval anchovy fishery were obtained from the Fangliao Fisherman Association. The monthly catch per unit of fishing effort (CPUE) was used as an estimate of the abundance of larval anchovy stocks from January 1980 to December 2000 (Fig. 2a). Data after December 2000 were not included in this analysis because a significant amount of non-random missing data existed in summers due to the initiation of governmental regulation of the anchovy fishery. Owing to the non-random feature, the missing data after December 2000 could not reasonably be estimated (Little and Rubin, 2002) (Fig. 2a). The random missing data between 1980 and 2000 (Fig. 2a) were estimated using the best fitting state-space model based on the Kalman filter (Durbin and Koopman, 2001).

For the same period (1980-2000), monthly sea surface temperature (SST) data were obtained from the oceanographic station on Xiaoliuqiu Island (Fig. 1). Monthly river flow data $\left(\mathrm{m}^{3} \mathrm{~s}^{-1}\right)$ of the Gaoping River, the main source of river runoff in the study area, were obtained from the Water Resource Agency, Minister of Economic Affairs (Fig. 1). Wind velocity $\left(\mathrm{m} \mathrm{s}^{-1}\right.$, every $\left.3 \mathrm{~h}\right)$ data were from the Hengchun Station of the Central Weather Bureau in Taiwan (Fig. 1). The turbulent mixing condition of the upper ocean was estimated by a wind-mixing index, which is proportional to the cube of the wind velocity (Bakun and Parrish, 1991). We calculated the mixing index based on the $3-\mathrm{h}$ wind data and then averaged this to monthly values. Values of the 
Figure 2. (a) Time series of monthly catch per unit effort (CPUE) of larval anchovy in the coastal area off southwestern Taiwan from 1980 to 2005. Triangles indicate estimated missing data. Only data from 1980-2000 (indicated by the dashed line) were used in the analysis. (b) Seasonality of CPUE. Two peaks (spring: February-May, and autumn: June-October) correspond to two main fishing seasons.
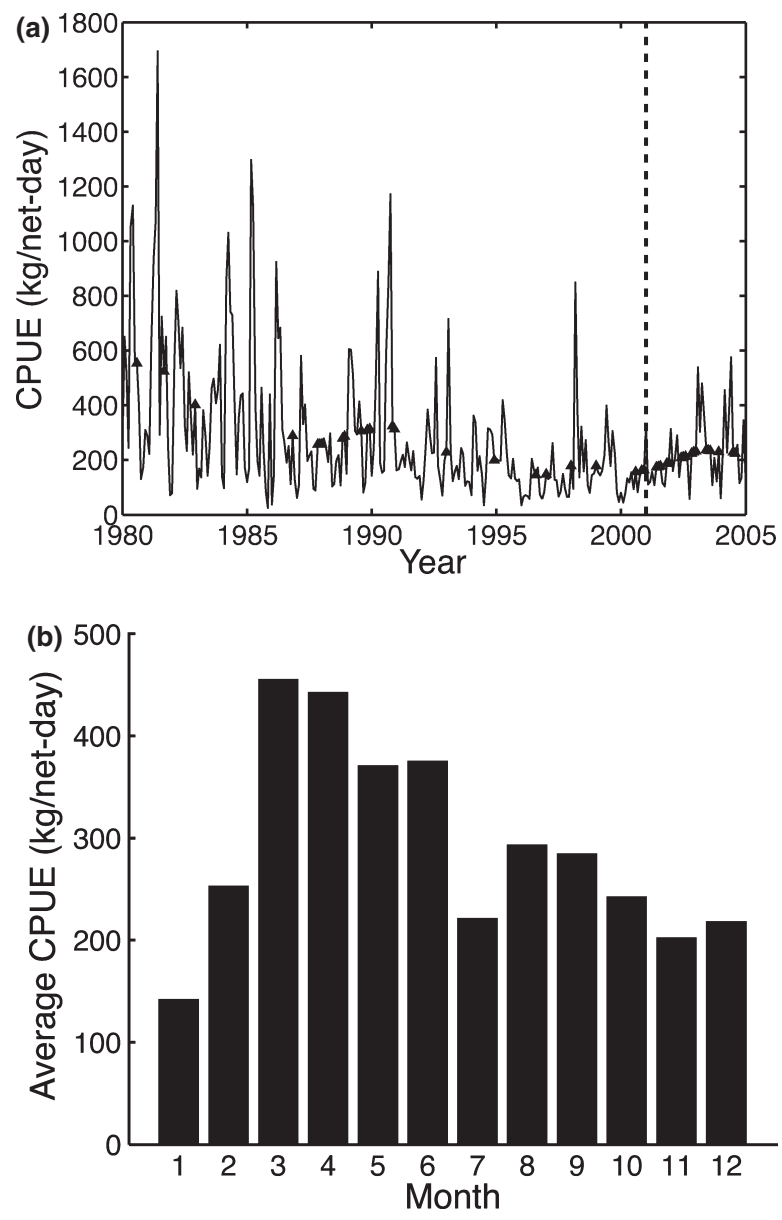

SOI (Trenberth, 1984) were obtained from the National Center for Atmospheric Research, USA (http://www.cgd.ucar.edu/cas/catalog/climind/soi.html).

Recent modeling and observational studies indicated that the SST in water off southwestern Taiwan increased during ENSO events because there was a weakening of the northeastern monsoon during ENSO and hence a reduction in the intrusion strength of the northern cold water mass (China Coastal Current) into the Taiwan Strait (Fig. 1) (Wu et al., 2007); that is, the local SSTs were positively correlated with El Niño. To avoid confusion, we use the negative SOI in analyses throughout this study so that the high positive values of the index indicate El Niño.

\section{Seasonality}

The seasonality of the anchovy CPUE was calculated by averaging long-term monthly values from 1980 to 2000. Generally, there was a major peak in spring and a minor peak in autumn in the CPUE (Fig. 2b). Throughout this study, the spring season is defined as February to May, and autumn season as June to October, consistent with the conventional terminology used in fishery regulations. (The autumn season actually corresponds to the summer-autumn season).

\section{Species composition}

From 1988 on, the compositions of the three main species (Eng. japonicus, Enc. heteroloba and Enc. punctifer) in the larval anchovy catch were estimated. Fish samples from the catch between February and May were lumped and identified to calculate the species composition in the spring season, and, likewise, samples between June and October were used to identify the composition in the autumn season (Fig. 3). We aggregated Enc. heteroloba and Enc. punctifer to represent the southern species.

\section{Signal decomposition}

Seasonality is apparent in the CPUE (Fig. 2) as well as the local environmental data (Fig. 4). Seasonal

Figure 3. Compositions of northern (Engraulis japonicus) and southern (Encrasicholina heteroloba and Encrasicholina punctifer) species and the seasonal average CPUE in the spring (February-May) (a) and summer-autumn (JuneOctober) (b) seasons, respectively. Black bars represent Eng. japonicus, and white bars Enc. heteroloba and Enc. punctifer. Gray solid lines represent the seasonally averaged CPUE. Significant correlations between CPUE and the proportion of Eng. japonicus were found in both seasons $(P<0.05)$ suggesting that the magnitude of the catch was determined by the seasonal strength of Eng. japonicus.

(a)
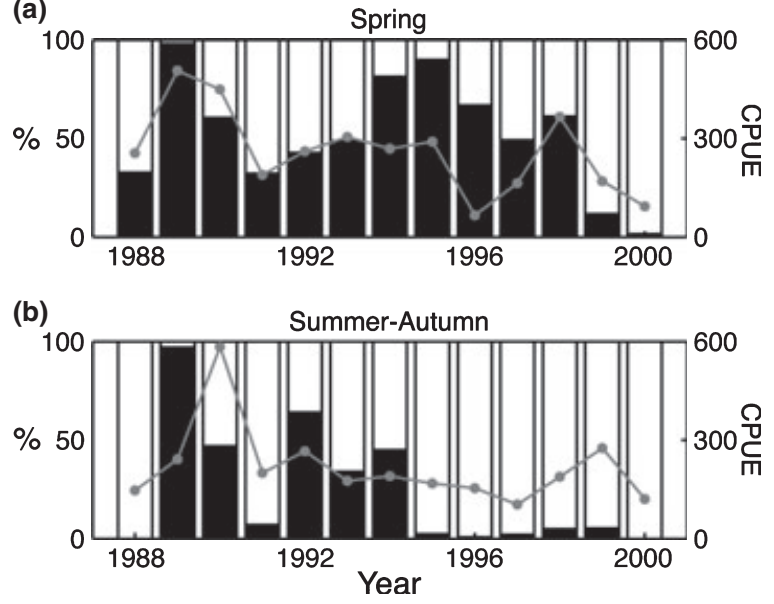
Figure 4. Time series of the monthly sea surface temperature (a), river runoff (b), and mixing index (c).

(a)
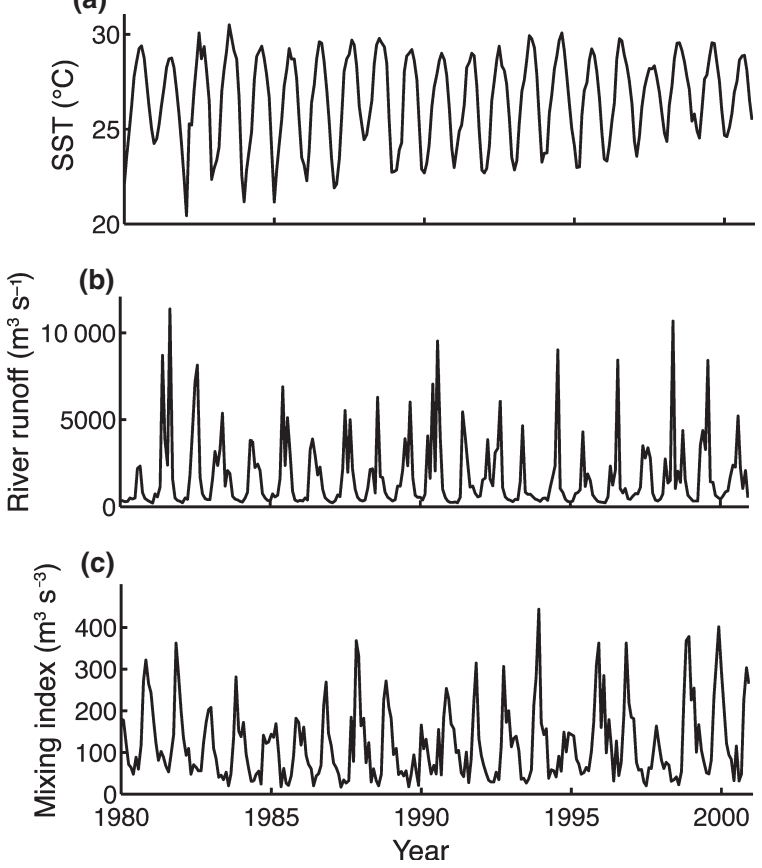

adjustment is a common practice in time series analysis to avoid strong seasonality masking other important signals (Casals et al., 2002). Traditionally, seasonal adjustment is carried out by removing longterm monthly means (e.g. Tsai et al., 1997) or by applying a symmetrical filter (e.g. Findley et al., 1998), which may cause spurious results (see the criticism in Casals et al., 2002). Herein, we employed the statespace structural decomposition approach, which is superior to those traditional approaches, to make seasonal adjustments (Casals et al., 2002).

We briefly describe the state-space time series approach. To fix the idea, we begin with the simplest local level model. The local level model (known as the random walk model) can be represented as:

$$
\begin{aligned}
y_{t}=\mu_{t}+\varepsilon_{t}, & \varepsilon_{t} \sim \operatorname{Normal}\left(0, \sigma_{\varepsilon}^{2}\right) \\
\mu_{t+1}=\mu_{t}+\zeta_{t}, \quad \zeta_{t} & \sim \operatorname{Normal}\left(0, \sigma_{\zeta}^{2}\right),
\end{aligned}
$$

where (1) is the observation equation, and (2) is called the state equation, for $t=1, \ldots, n$, where $y_{t}$ is the observed variable at time $t$ (or the time series datum), and $\mu_{t}$ is called the state variable (or hidden variable) determining the behavior of $y_{t}$ at time $t, \epsilon_{t}$ is the observation disturbance at time $t$, and $\zeta_{t}$ is the level disturbance at time $t$. The observation and level disturbances are assumed to be normally distributed and serially and mutually independent. Under the assumption of multivariate normal distribution, given $\sigma_{\varepsilon}^{2}, \sigma_{\zeta}^{2}$ along with $\mu \sim \operatorname{Normal}\left(a_{1}, P_{1}\right)$ (initialization), $\mu_{t}$ can be estimated sequentially when new $y_{t}$ added. The $\sigma_{\varepsilon}^{2}, \sigma_{\zeta}^{2}, a_{1}$ and $P_{1}$ can be estimated by a likelihood approach, and the updating can be done with Kalman filter and fixed-interval smoother (Durbin and Koopman, 2001; Casals et al., 2002).

This local level model can be generalized to include trend and seasonality as follows:

$$
\begin{aligned}
& y_{t}=\mu_{t}+v_{t}+\gamma_{t}+\varepsilon_{t}, \quad \varepsilon_{t} \sim \operatorname{Normal}\left(0, \sigma_{\varepsilon}^{2}\right) \\
& \mu_{t+1}=\mu_{t}+\zeta_{t}, \quad \zeta_{t} \sim \operatorname{Normal}\left(0, \sigma_{\zeta}^{2}\right) \\
& v_{t+1}=v_{t}+\xi_{t}, \quad \xi_{t} \sim \operatorname{Normal}\left(0, \sigma_{\xi}^{2}\right) \\
& \gamma_{t+1}=-\sum_{j=1}^{s-1} \gamma_{t+1-j}+\omega_{t}, \quad \omega_{t} \sim \operatorname{Normal}\left(0, \sigma_{\omega}^{2}\right),
\end{aligned}
$$

where $v_{t}$ represents the trend component (considered as the slope), and $\gamma_{t}$ represents the seasonal component with $j$ indicating the $j$ th month. Similarly, $\mu_{t}, v_{t}$ and $\gamma_{t, j}$ can be estimated using the aforementioned procedure. By so doing, a time series is decomposed into trend (including cycles), seasonal, and irregular components: $y_{t}=s_{t}+\gamma_{t}+\epsilon_{t}$, where $s_{t}=\mu_{t}+v_{t}$. The theory of state-space time series analysis is well presented in Durbin and Koopman (2001). Free MATLAB software to carry out this decomposition is available from the $E^{4}$ team (http://www.ucm.es/info/icae/e4/). As we were interested in interannual variability, we used only the trend-cycle component (Fig. 5) in the correlation, regression, and wavelet analysis.

\section{Wavelet analysis}

To investigate environmental effects on fluctuations of the anchovy population, we first examined their periodicities. Fourier spectral analysis is the most common approach in analysing periodicity of time series data; however, it assumes that the time series is stationary. Apparently, our anchovy CPUE time series (Fig. 5a) is not stationary. Therefore, we used wavelet analysis that requires no assumption of stationarity and has the ability to determine the dominant modes of variability in frequency and how those modes vary over time (Torrence and Compo, 1998; Menard et al., 2007).

The wavelet transform is based on the convolution between a time series $y_{n}(n=0, \ldots, N-1$, with equal spacing $\delta \mathrm{t}$ ) and a wavelet function. Here we use the Morlet wavelet function:

$$
\psi_{0}(\eta)=\pi^{-1 / 4} e^{i \varpi_{0}} e^{-\eta^{2} / 2}
$$

where $\eta$ is the dimensionless time parameter and $\omega_{0}$ is the dimensionless frequency taken to be 6 to balance 
Figure 5. Long-term trends and cycles of the CPUE (a), SST (b), river runoff (c), mixing index (d), and the negative SOI (e) after seasonal adjustments. Values are normalized to the unit mean and variance. The dashed line indicates the long-term linear trend of each variable.
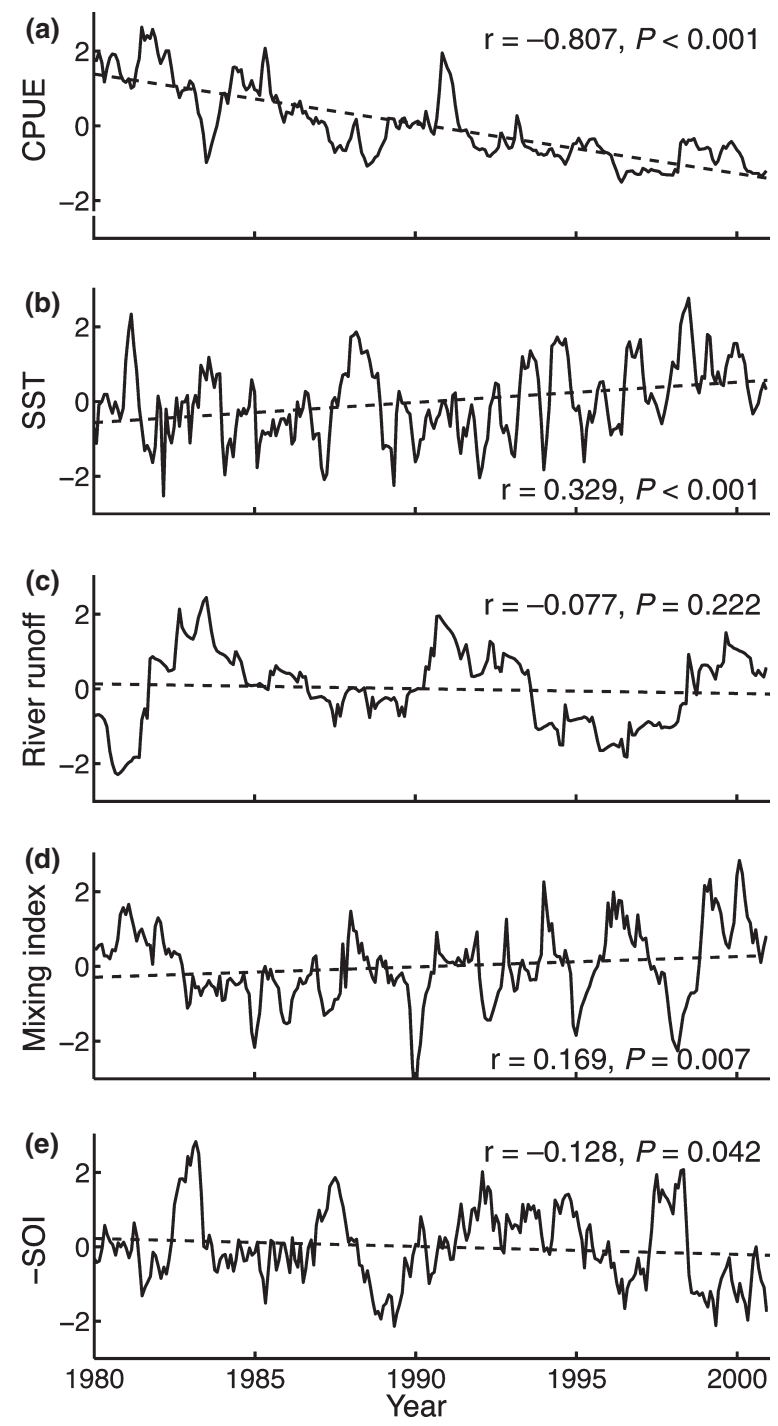

between time and frequency localization (Torrence and Compo, 1998). The wavelet transform of $y_{n}$ is:

$$
W_{n}^{y}(s)=\sqrt{\frac{\delta t}{s}} \sum_{n^{\prime}=1}^{N} y_{n^{\prime}} \psi_{0}\left[\left(n^{\prime}-n\right) \frac{\delta t}{s}\right],
$$

where $s$ is called the scale so that $\eta=$ st. By varying $s$, the wavelet is stretched in time. In practice, this is easier to do in the Fourier space. The Fourier transform of $y_{n}$ is

$$
\hat{y}_{k}=\frac{1}{N} \sum_{n=0}^{N-1} y_{n} e^{-2 \pi i k n / N}
$$

(c) 2009 The Authors, Fish. Oceanogr., 18:2, 102-117. where $k=0, \ldots, N-1$ is the frequency index. The Fourier transform of $\psi(t s)$ is given as $\hat{\psi}(s \omega)$. By convolution theory, the wavelet transform of $y_{n}$ is the inverse Fourier transform of the product of $\hat{y}_{k}$ and $\hat{\psi}(s \omega)$, as follows:

$$
W_{n}^{y}(s)=\sum_{k=0}^{N-1} \hat{y}_{k} \hat{\psi}\left(s \omega_{k}\right) e^{i \omega_{k} n \delta t}
$$

Wavelet transform was applied to our time series data. As we were interested in the interannual variability, the long-term linear trend was removed prior to the wavelet analysis. The 5\% significance level was determined based on bootstrap simulations (1000 times) taken as an order-1 autoregressive process. The autoregression coefficient was obtained empirically from the time series data.

We then carried out cross-wavelet coherence and phase analyses to investigate causal relationships between the environmental variables and larval anchovy as well as the relationships between the SOI and local environmental variables. We do not present the cross-wavelet spectrum because it describes common power of two series without normalizing to the power of single series and may give misleading information (Maraun and Kurths, 2004). For example, when one of the spectra is flat and the other exhibits strong peaks, the cross-wavelet spectrum may show significant peaks which do not necessarily indicate strong correlation between these two signals. By contrast, cross-wavelet coherence represents cross-correlation normalized to the power of single process (Grinsted et al., 2004) and hence is not biased by the power of any single series (Maraun and Kurths, 2004).

The cross-wavelet transform of two series, $x_{n}$ and $y_{n}$, is defined as $W^{X Y}=W^{X} W^{Y^{*}}$ where $*$ denotes complex conjugation. The wavelet coherency is defined as:

$$
R_{n}^{2}(s)=\frac{\left|S\left(s^{-1} W_{n}^{X Y}(s)\right)\right|^{2}}{S\left(s^{-1} W_{n}^{X}(s)\right)^{2} \cdot S\left(s^{-1} W_{n}^{Y}(s)\right)^{2}},
$$

where $S$ is a smoothing operator by running average (Torrence and Webster, 1999). The wavelet coherency phase is:

$$
\phi_{n}(s)=\tan ^{-1}\left(\frac{\operatorname{Imaginary}\left\{S\left(s^{-1} W_{n}^{X Y}(s)\right)\right\}}{\operatorname{Real}\left\{S\left(s^{-1} W_{n}^{X Y}(s)\right)\right\}}\right) .
$$

Both $R_{n}^{2}(s)$ and $\varphi_{n}(s)$ are functions of the time index $n$ and the scale $s$. The details of the mathematics and calculations can be found in Torrence and Compo (1998) and Grinsted et al. (2004). Free MATLAB software has been made available by Torrence and Compo (http://atoc.colorado.edu/research/wavelets/) 
and by Grinsted, Moore, and Jeveveva (http:// www.pol.ac.uk/home/research/waveletcoherence/).

\section{Correlation analysis}

In addition to the periodicities in the time series, we examined direct correlations between the anchovy CPUE and environmental variables using a crosscorrelation analysis. We investigated the effects of one global index $(-\mathrm{SOI})$ and three local hydrographic variables (SST, river runoff, and mixing index) with a lag time of up to 12 months (corresponding roughly to the life span of the anchovy). We also investigated the relationship between the negative $\mathrm{SOI}$ and the three local variables with a lag time of up to 24 months (to capture the time-delayed responses of the environmental variables to ENSO). As we were interested in interannual variations, the long-term linear trend was removed prior to the correlation analysis.

One important issue in testing correlation between time series is to account for the autocorrelation structure in the time series. Several approaches have been proposed to remedy this problem; for example, removing the autocorrelation by taking the first difference (Tsai et al., 1997), adjusting the effective degrees of freedom (Pyper and Peterman, 1998), or estimating the parametric autocorrelation structure in the analysis (Ives and Zhu, 2006). Here, we used a stationary bootstrap procedure to test the correlation. The idea behind the stationary bootstrap is to resample the time series while preserving the autocorrelation structure in the resampling procedure as follows. Firstly, randomly draw $X_{1}$ from the original time series. Second, with probability $p, X_{2}$ is drawn randomly, and with probability $(1-p), X_{2}$ is chosen as the 'next' observation from the original series following $X_{1}$. The probability $p$ is determined based on the autocorrelation structure of the original time series (Politis and White, 2004). This procedure was carried out 1000 times to compute the $95 \%$ confidence limits of the correlation coefficient and perform the hypothesis test (Politis and Romano, 1994), and 95\% confidence limits were calculated using the accelerated bias correction method (Efron and Tibshirani, 1986). This approach is nonparametric and accounts for autocorrelation in the time series. The free MATLAB software to estimate probability $p$ and carry out stationary bootstrap is available from Patton (http://www. economics.ox.ac.uk/members/andrew.patton/code.html).

\section{Multivariate moving window regression}

We suspected that the relationship between the anchovy CPUE and environmental variables was not persistent over time. Although the wavelet coherent analysis is perfectly capable of investigating nonstationary relationships between the CPUE and environmental variables, it does so univariately. The theory of multivariate wavelet model selection and inference is not yet conclusive. Therefore, we devised a multivariate moving-window regression analysis to help visualize the relationship. We predetermined a window size, investigated the relationship between the CPUE and environmental variables (including their lags up to 12 months) based on stepwise selection, and tested the relationship with the stationary bootstrap. We then slid the window forward once a year and repeated the same testing procedure. We used a $10-y r$ window to roughly capture two ENSO cycles. Using a 10-yr window, we also attempted to match two dominant cycles of CPUE fluctuations (Fig. 6a). Again, the long-term linear trend was removed prior to analysis. The moving-window regression coefficients were used to infer the strength of associations between the CPUE and environmental variables over time. The coefficients should be treated with caution, however, because tests based on a sliding window are not independent.

\section{RESULTS}

\section{Species composition}

The anchovy CPUE exhibited seasonality with a major peak in spring and a minor peak in autumn (Fig. 2b). In spring, the northern and southern species had similar proportions (with long-term averages of $52 \%$ and 48\%, respectively; Fig. 3a), whereas in autumn, the southern species was dominant (with a long-term average of $72 \%$; Fig. 3b). The species compositions in spring (Fig. 3a) and autumn (Fig. 3b) changed over time. Interestingly, the fraction of northern species in spring was positively correlated with the spring CPUE (averaged from February to May; $r=0.591, P<0.05$, stationary bootstrap test of correlation) and the fraction in autumn was positively correlated with the autumn CPUE (from June to October; $r=0.438, P<0.05$, stationary bootstrap test of correlation). These positive correlations suggested that the magnitude of the anchovy CPUE was determined by the seasonal strength of Japanese anchovy in the coastal waters off southwestern Taiwan, and this was more pronounced in spring, the major fishing season. No significant correlation was found between the proportions of Japanese anchovy in spring and summer within the same year $(r=0.450, P>0.05$, stationary bootstrap test of correlation), indicating that a relatively high abundance of Japanese anchovy in spring did not necessarily result in a relatively high abundance later in autumn. 
Figure 6. Wavelet power spectrum (left) and global power spectrum (right) of CPUE (a), SST (b), river runoff (c), mixing index $(\mathrm{d})$, and the negative $\mathrm{SOI}$ (e). The local wavelet power spectrum provides a measure of the variance distribution of the time series according to time and for each periodicity; high variability is represented by red, and weak variability by blue. The solid black contour encloses regions of $>95 \%$ confidence for a red-noise process with a lag-1 coefficient, and the shadowed area indicates the cone of influence (COI) where edge effects become important. For the global power spectrum, the dashed line indicates the $5 \%$ significance level for the same red-noise process. Periods corresponding to the peaks are indicated; however, not all annotated peaks were significant at the 95\% confidence level.

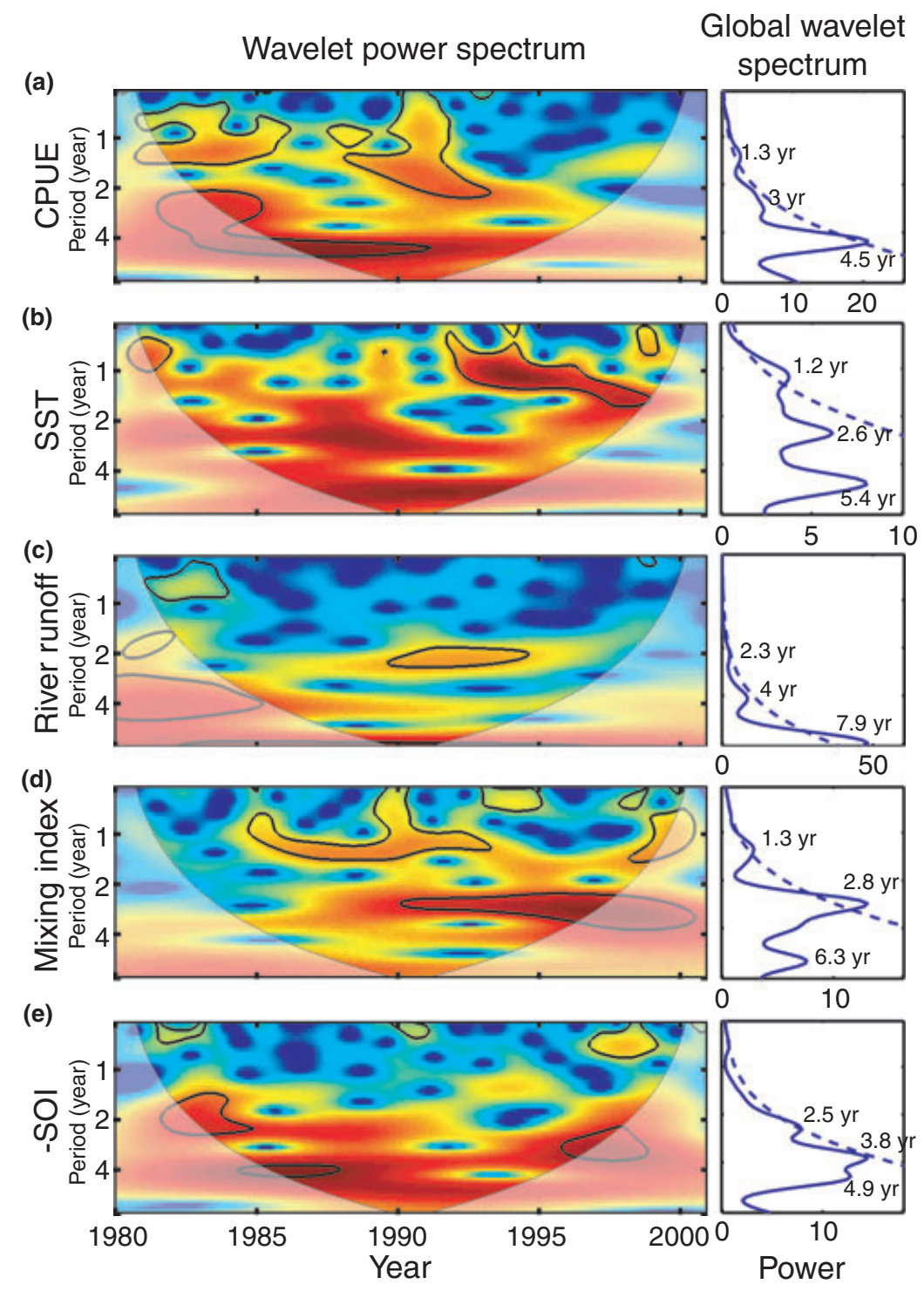

Signal decomposition and the long-term trend

The signal decomposition procedure effectively removed the seasonality from the time series data (Fig. 5). Albeit with interannual variations, the anchovy CPUE (Fig. 5a) and negative SOI (Fig. 5e) exhibited a long-term declining trend over the 21-yr period, whereas the SST (Fig. 5b) and mixing index (Fig. 5d) exhibited long-term increasing trends.

\section{Interannual variability}

The fact that the mode of variability of the frequency changed over time, according to the wavelet analysis (based on detrended data), implies that the time series of anchovy CPUE and environmental variables were not stationary (Fig. 6). The CPUE exhibited a high-frequency cycle of c. $1.3 \mathrm{yr}$ and an intermediate-length cycle of 4-5 yr from the 1980s to the early 1990s (Fig. 6a). The SST showed c. 1.2yr periodicity in the later part of the series (Fig. 6b); the river runoff showed c. 2.3-yr periodicity in the early 1990s (Fig. 6c); the mixing index showed c. 1.3-yr periodicity from 1985 to 1993 and c. 2.8-yr periodicity after 1990 (Fig. 6d); the negative SOI showed 2-and 4-yr periodicity in the early period and 3- to 4-yr periodicity around 1996-1998 (Fig. 6e).

Cross-wavelet coherence and phase analysis indicated the non-stationary (transient) relationship between the anchovy CPUE and the environment (Fig. 7). The wavelet coherency is equivalent to the correlation coefficient and the phase represents the time lag (Torrence and Compo, 1998). Significant 
Figure 7. Cross-wavelet coherence between environmental variables: SST (a), river runoff (b), mixing index (c), and negative SOI (d), and CPUE. The solid black contour encloses regions of $>95 \%$ confidence for a red-noise process with a lag- 1 coefficient, and the shadowed area indicates the cone of influence (COI) where edge effects become important. The phase relationship is shown as arrows, with in-phase pointing right, anti-phase pointing left, and CPUE leading the environmental variable by $90^{\circ}$ pointing straight up.
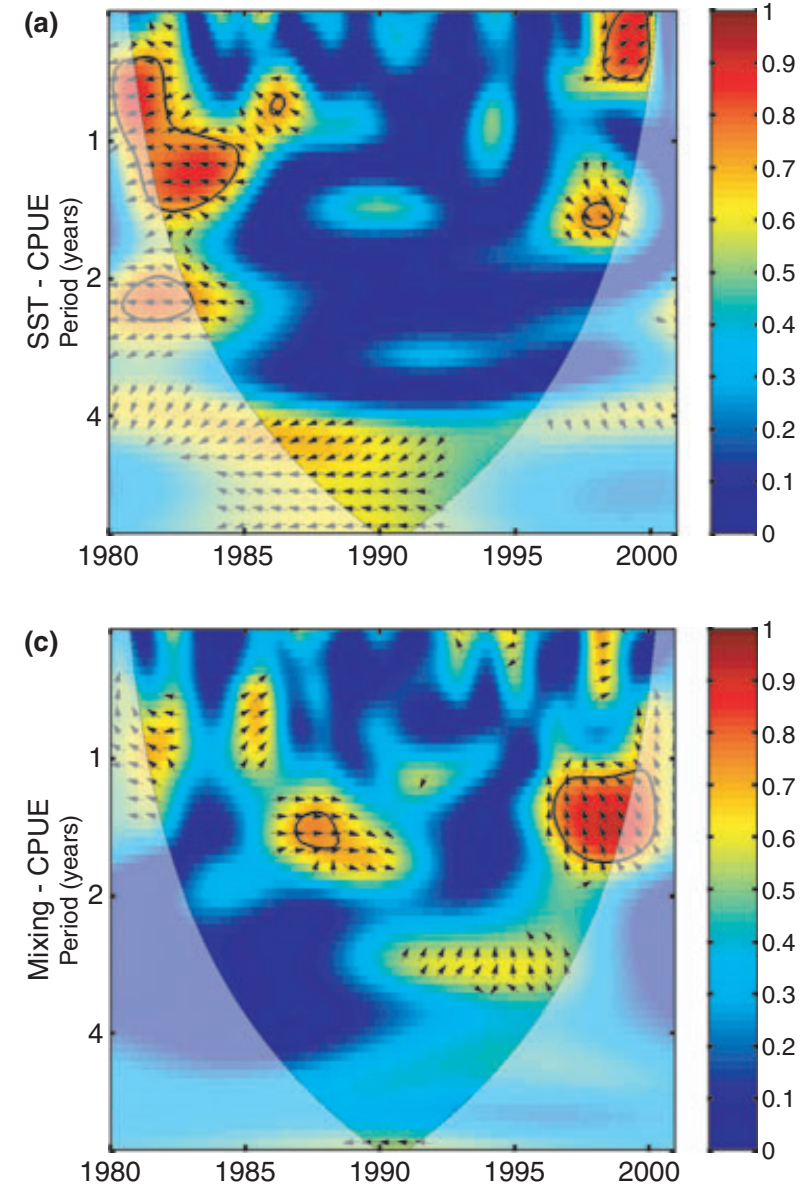

coherency between the CPUE and SST was found only from 1980 to 1987 with a periodicity c. $0.5-1.3 \mathrm{yr}$ and they showed an anti-phase, indicating a negative correlation (Fig. 7a). The CPUE and river runoff showed significant coherence after 1988 with a periodicity c. $1-2.3 \mathrm{yr}$ and most of the correlations are in-phase, suggesting a positive correlation (Fig. 7b). A possible negative relationship existed between the CPUE and mixing effects with the mixing index leading the CPUE by roughly 10 months since 1996 (Fig. 7c). No strong relationship was found between the CPUE and negative SOI other than the possible intermediate frequency of 5 yr before 1990 (Fig. 7d); this correlation represents negative effects of ENSO events on the larval anchovy. Note that significant peaks of small areas were omitted in the wavelet analysis because these peaks may represent spurious
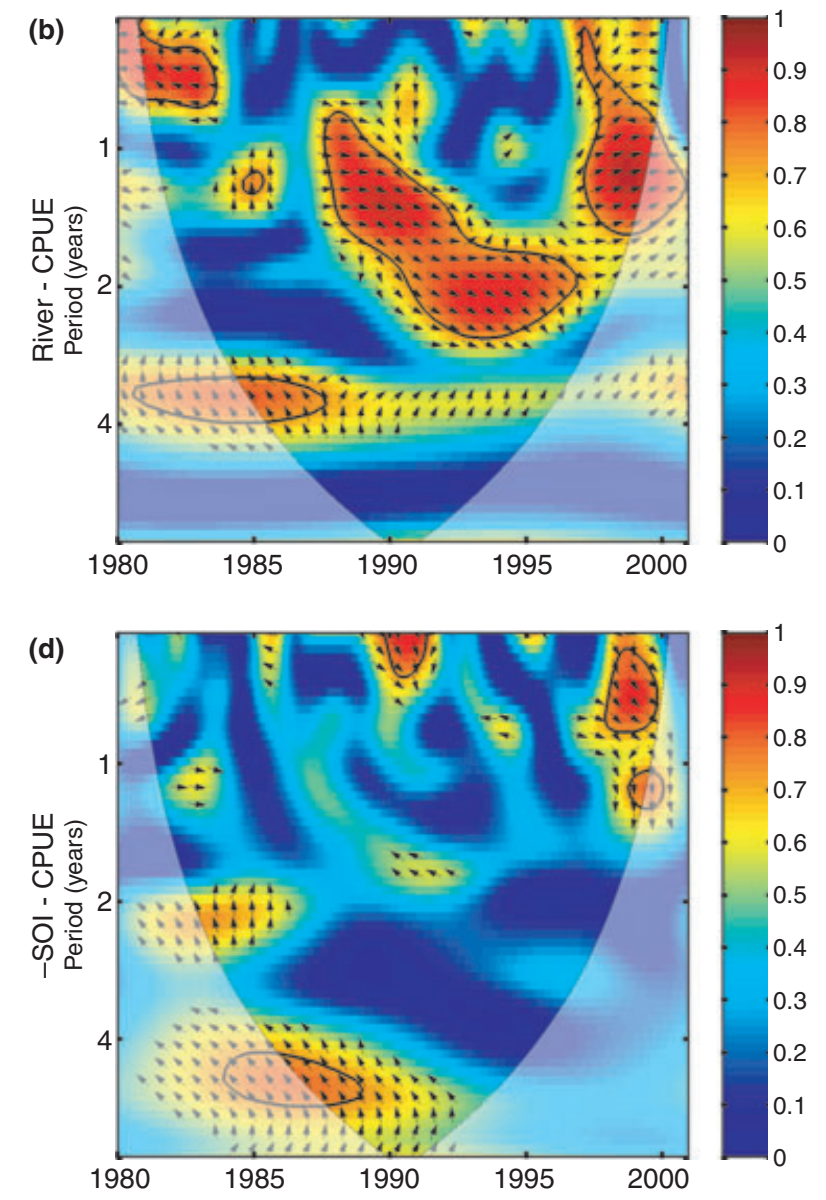

correlations resulting from multiple testing (Maraun and Kurths, 2004).

Wavelet coherence analysis revealed a stationary relationship between the SOI and SST (Fig. 8a), no direct relationship between the negative $\mathrm{SOI}$ and river runoff (Fig. 8b), and a non-stationary relationship between the negative SOI and mixing condition (Fig. 8c). The SST and negative SOI exhibited significant correlations with a periodicity of $2-3 \mathrm{yr}$ before 1990 and another periodicity of c. 4-7 yr throughout the study period (Fig. 8a). This result corroborated the known phenomenon that ENSO increases the SST in the waters southwest of Taiwan through its effects on the Asian monsoon (Wu et al., 2007). The mixing index and negative SOI showed a significant negative correlation from 1988 to 1993 with a periodicity of c. 1-1.3 yr and another 
Figure 8. Cross-wavelet coherence between the negative SOI and local environmental variables: SST (a), river runoff (b), and mixing index (c). See Fig. 6 for legends.
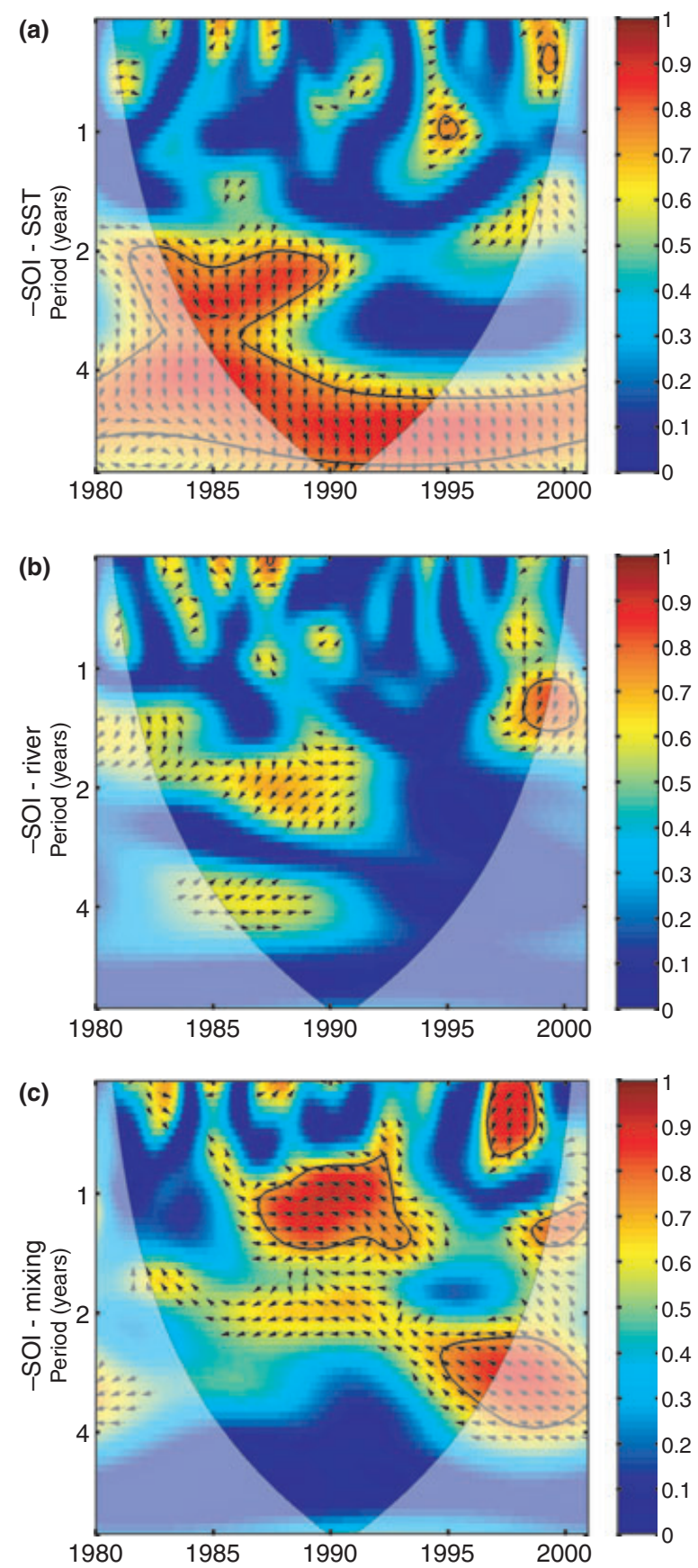

significant negative correlation after 1995 with a periodicity of c. 2.5-4 yr (Fig. 8c).

Considering the entire $21 \mathrm{yr}$ of data, the anchovy CPUE (detrended data) was negatively correlated with the negative SOI (detrended data) with a lag of 5 months (Table 1 ). We found no further significant
Table 1. Correlations of the CPUE with local hydrographic variables (SST, river runoff, and mixing index) and the negative SOI, and correlations of the negative SOI with local hydrographic variables for the period from 1980 to 2000.

\begin{tabular}{lll}
\hline & CPUE & - SOI \\
\hline SST & N.S. & $\begin{array}{r}r=0.293, \\
\text { lag }=9 \text { months }\end{array}$ \\
River runoff & N.S. & N.S. \\
Mixing index & N.S. & N.S. \\
-SOI & $r=-0.294$, & \\
& $\operatorname{lag}=5$ months & \\
\hline
\end{tabular}

The best significant correlations are reported. N.S. represents non-significance for all lags based on the stationary bootstrap analysis with $\alpha=0.05$. For the CPUE, we tested the lag correlation up to 12 months, corresponding to the life span of anchovy; for the negative SOI, we tested the lag correlation up to 24 months to capture the time-delayed responses.

correlation of the CPUE with local hydrographical variables for the entire time series. We did find a significant positive correlation between the negative SOI and SST with a lag of 9 months (Table 1).

The moving-window regression analysis corroborated the conclusions from wavelet analysis; that is, relationships between the CPUE and environmental variables were not persistent over time (Fig. 9). In the early period CPUE was negatively affected by linear combination of lagged SST, SOI and river runoff. A significant positive correlation between the CPUE and river runoff with a lag of $0-3$ months started from 1984 on (Fig. 9). The mixing conditions negatively affected the CPUE with a lag of 9-11 months since 1988 (Fig. 9). The results of moving-window regression analysis are not exactly identical to those of the wavelet analysis because the regression analysis employed a 10-yr moving window whereas the wavelet analysis investigated various windows. Nevertheless, the findings are similar; that is, no single local hydrographic factor could explain the variability of the CPUE for the entire period.

\section{DISCUSSION}

The larval anchovy fishery in coastal waters off southwestern Taiwan consists mainly of a northern species (Eng. japonicus) and two southern species (Enc. heteroloba and Enc. punctifer) and exhibits a major peak in spring and a minor peak in autumn (Fig. 2). These features were also found in the larval anchovy catch off northeastern Taiwan (Chiu et al., 1997). The 


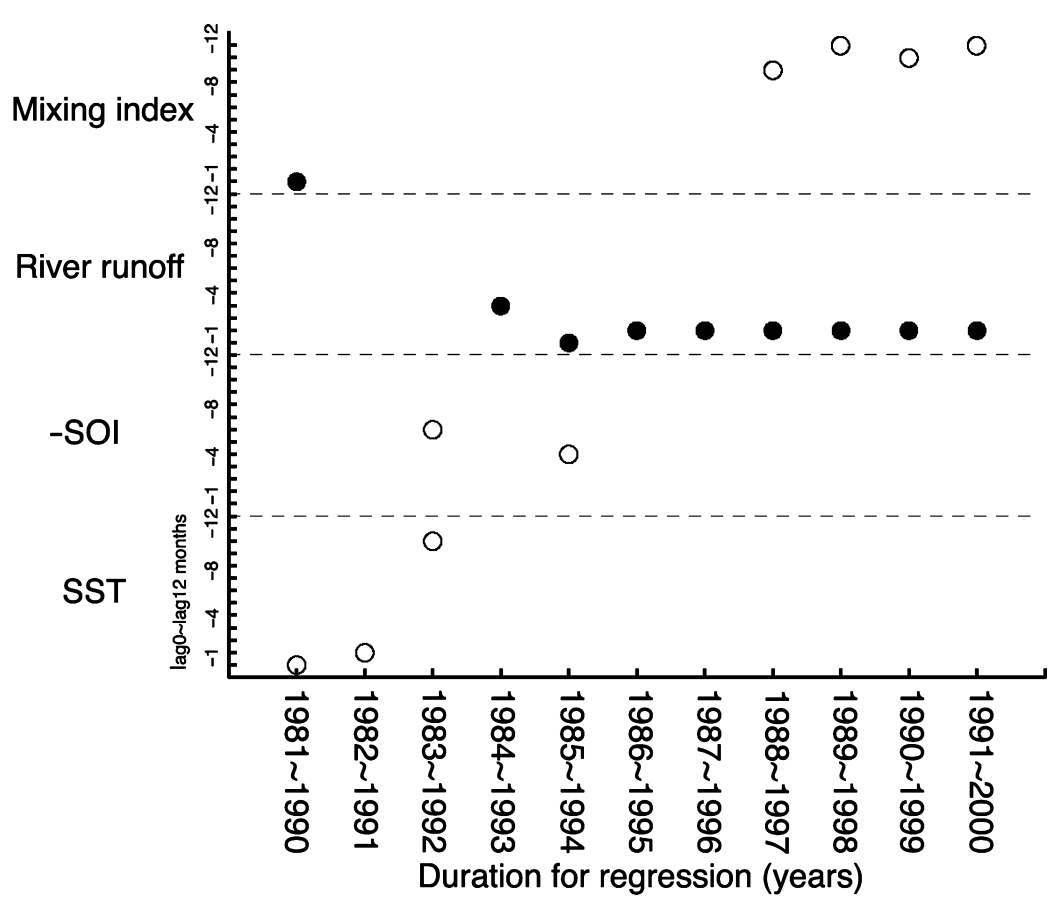

Figure 9. Results of multivariate moving-window (of $10 \mathrm{yr}$ ) regression analyses showing the significant correlation of the CPUE with the SST, negative SOI, river runoff, and mixing index. Filled circles, positive effect; open circles, negative effects. Only significant results are presented (stationary bootstrap, $P<0.05)$. The $x$-label indicates the decade that is used in regression analysis. The $x$-label starts from 1981 because we considered lags up to 12 months. For each environmental variable, we tested data from lag 0 to 12 months. The results show that relationships between the CPUE and environmental variables were non-stationary. spring peak consisted of both the northern and southern species with their relative contributions varying interannually (Fig. 3a), whereas the autumn peak was dominated by the southern species (Fig. 3b). Such seasonal variations in the species composition (Fig. 3) may reflect seasonal changes in the oceanic circulation patterns around Taiwan. In spring, when the northeasterly monsoon prevails, the China Coastal Current (CCC) moves southward into the Taiwan Strait, and the Kuroshio Branch Current (KBC) also intrudes into the southern Taiwan Strait (Fig. 1) (Jan et al., 2002). Very likely, the northern species take advantage of the southerly moving CCC, and the southern species ride the northerly moving $\mathrm{KBC}$ to reach their spawning grounds, the coastal area off southwestern Taiwan, in spring. In autumn, when the southwesterly monsoon is strong, the South China Sea Surface Current (SCSSC) moves northward into the Taiwan Strait (Fig. 1) (Jan et al., 2002). Therefore, it is reasonable to assume that the SCSSC brings in the southern species in autumn. However, the appearance of the northern species in autumn is unexpected because the currents flow mainly northerly in the Taiwan Strait and East China Sea during this season (Lee and Chao, 2003). Notably, a similar autumn peak of the northern species was also observed in the coastal waters off northeastern Taiwan (Chiu and Chen, 2001). One possible explanation is that the northern species may swim southward to reach their spawning ground along the coast of Mainland China where the north- erly flow is very weak and not persistent in autumn (Lee and Chao, 2003). To test this hypothesis, trawling surveys along the transect from the coast to the continental break in the southern East China Sea are necessary in the future. Such surveys will also help delineate the migratory routes of the northern species.

An interesting finding is that the seasonal strength of the anchovy CPUE is significantly related to the fraction of the northern species (Japanese anchovy), particularly in the major fishing season (spring) (Fig. 3). This result indicates that the annual catch of anchovy may be determined mainly by the yearly strength of the northern species rather than by the two southern species, at least since 1988, when species composition data became available. Facing problems of limited resources and funding in managing the anchovy fisheries of Taiwan, our finding suggests that focusing research on the northern species may be more cost-effective. Furthermore, estimating species composition in the catch will be essential for effective management plans.

The main factor that caused the interannual variation of anchovy CPUE may change with time (Figs 6, 7 and 9). A previous study based on data from 19801992 suggested that fluctuations in the anchovy population were affected mainly by local SST, which in turn was determined by the SOI (Tsai et al., 1997). Such a relationship only existed in the early period (Figs $7 \mathrm{a}$ and 9) and is rendered transient when the updated data were considered with non-stationary analytical methods (Table 1, Figs 7a and 9). One 
might suspect that the negative temperature effects could arise because such a high temperature exceeded the optimal survival or growth condition of larval anchovy (Takasuka et al., 2007); alternatively, the SST could simply be indicative of SOI (Table 1) and its effects on ocean current flux current. We observed positive (roughly in-phase) effects of river runoff since 1984 (Figs 7b and 9). The positive effects of river runoff may be related to a condition of elevated nutrients (Lloret et al., 2004). Negative effects of mixing conditions were found in the latter period (Figs 7c and 9). One might consider that the negative effects of increased mixing might be caused by elevated turbulent conditions that are detrimental to larval survival (Wroblewski and Richman, 1987); however, this cannot explain the lag effect of as long as 9-11 months. These results suggest that local environmental factors potentially affect larval survival. Although our investigation suggests transient relationships between abundance of larval anchovy and environmental variables in the coastal waters southwest of Taiwan, we cannot rule out the possibility that such transient relationships resulted partially from changes in species composition, particularly for the period before 1988 when no species composition data were available. However, transient relationships remained during the period from 1988 to 2000 (Figs 7 and 9).

The conclusion of transient relationships holds even when we divided the CPUE into northern (Eng. japonicus) and southern species (Enc. heteroloba and Enc. punctifer) based on the species composition data for the period from 1988 to 2000. We calculated seasonal CPUE by averaging the monthly CPUE into spring (February-May) and autumn (June-October) seasons and decomposed the averaged seasonal CPUE into the two species complexes because we have only two compositional data for the species each year (spring and autumn). We then used the wavelet coherence analysis (following the procedures described in Materials and Methods) to investigate relationships between environmental variables and northern and southern species, respectively. Our results suggested that the relationships were still non-stationary (Fig. 10a-d,f-j). The patterns for the northern species (Fig. 10a-d) and southern complex (Fig. 10f-j) are different, suggesting that the two species complexes should be managed separately. However, we do not attempt to over-interpret these results of wavelet coherence and phase analyses, because our sample size is limited in this case (only two data points each year for the duration from 1988 to 2000). We further employed wavelet coherence and phase analyses using the total CPUE versus the northern and southern species, respectively. The CPUE of northern species were largely consistent with the total CPUE (Fig. 10e), suggesting that the CPUE of northern species may be indicative of the total CPUE as mentioned before. By contrast, the CPUE of southern species were not as consistent with the total CPUE, except for the low-frequency (3-4 yr) fluctuations with a roughly half-year lag (Fig. 10j).

It is not surprising to see complex environmental effects on biological populations. Fluctuations of anchovy populations might not simply be determined by any single environmental factor; rather, those ups and downs may be determined by nonlinear combinations of several environmental factors (Hsieh et al., 2005, 2008). For example, temperature may be the limiting factor for the early period whereas food, for which river runoff is a proxy, may be the limiting factor for the latter period. The anchovy only prosper when several conditions are met simultaneously.

Furthermore, our analyses focused on examining local hydrographic effects on anchovy populations as emphasized by other studies (Lee et al., 1995; Lee and Lee, 1996; Tsai et al., 1997;. Hsia et al., 1998, 2004; Lloret et al., 2004). However, the dynamic of the anchovy populations in the coastal waters off southwestern Taiwan may be affected not only by local hydrographic conditions but also by influxes driven by ocean currents. Previous studies in the coastal regions of Taiwan might have over-emphasized the importance of local water temperature (Lee et al., 1995; Lee and Lee, 1996; Tsai et al., 1997; Hsia et al., 1998, 2004), which might mislead the management strategy for Taiwan anchovy fisheries. Our analyses indicated that the local SST was not a predictor to the fluctuations of larval anchovy around Taiwan.

While the effects of local hydrographic conditions were complex, a negative effect of ENSO events was observed for the whole $21 \mathrm{yr}$ (Table 1 and Fig. 7d). Although the relationship is significant, the ENSO explained $<10 \%$ of the variance (Table 1 ). In fact, this correlation was driven completely by the low frequency ENSO events; that is, the larval anchovy population plummeted during ENSO events between 1980 and 1990 (Fig. 5a,e). Negative effects of the ENSO on the anchovy population were also found in the California Current Ecosystem (Fiedler et al., 1986) and Humboldt Current Ecosystem (Alheit and Niquen, 2004). In the case of the California and Humboldt Current Ecosystems, strong ENSO events reduced nutrient upwelling and caused detrimental effects on anchovy. However, the ENSO events were not related to upwelling around Taiwan. Rather, the ENSO events changed the 
Figure 10. Cross-wavelet coherence between environmental variables and CPUE for the northern species (Engraulis japonicus) $(\mathrm{a}-\mathrm{d})$ and southern species (Encrasicholina heteroloba + Encrasicholina punctifer) $(\mathrm{f}-\mathrm{j})$. Cross-wavelet coherence between total CPUE and the northern species (e) and southern species $(j)$ was also shown. See legend in Fig. 7 for interpretation.
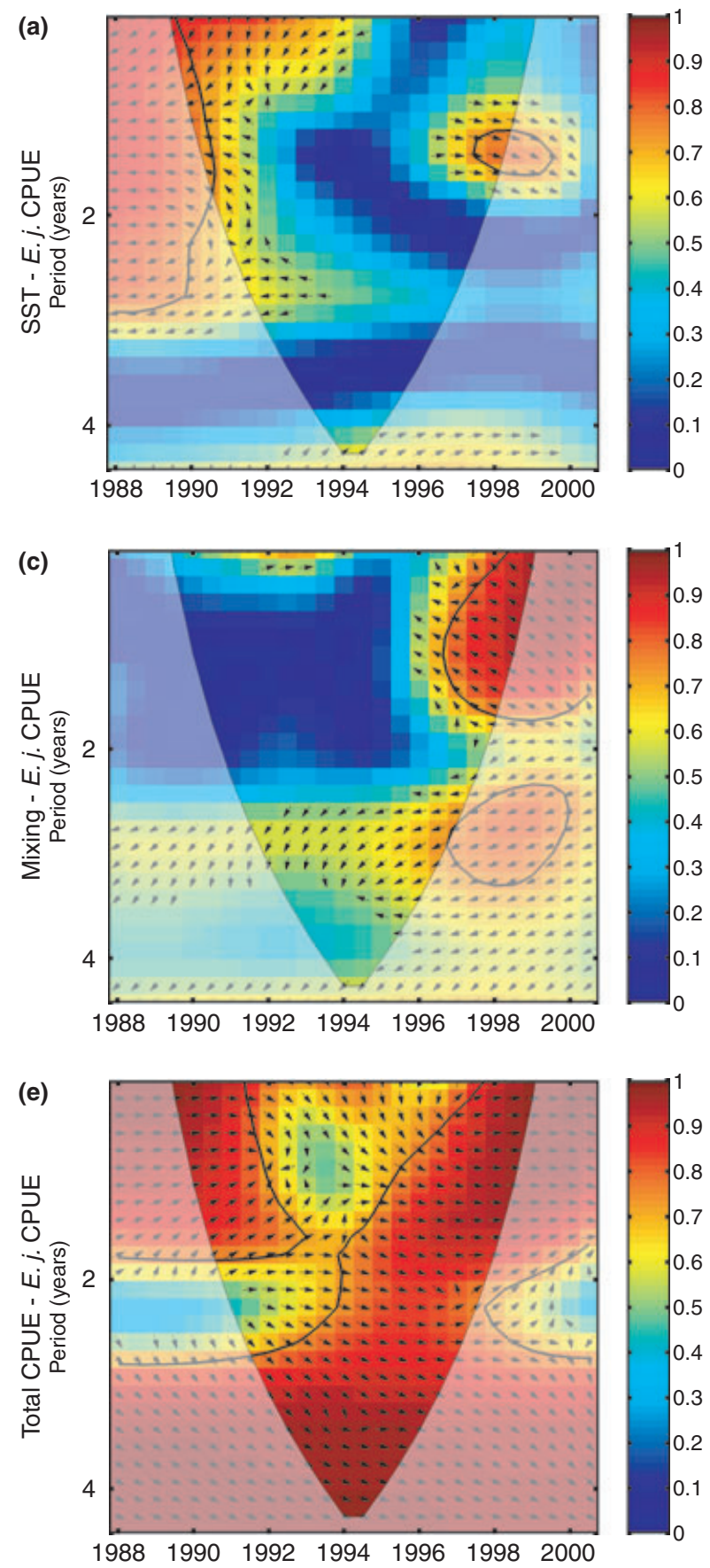

circulation pattern by affecting the North Pacific Asian monsoon dynamics (Jhun and Lee, 2004; Zhu et al., 2005). In the East China Sea and Taiwan Strait where the Japanese anchovy perform a spawning migration, the ENSO events reduced the monsoon, which in turn
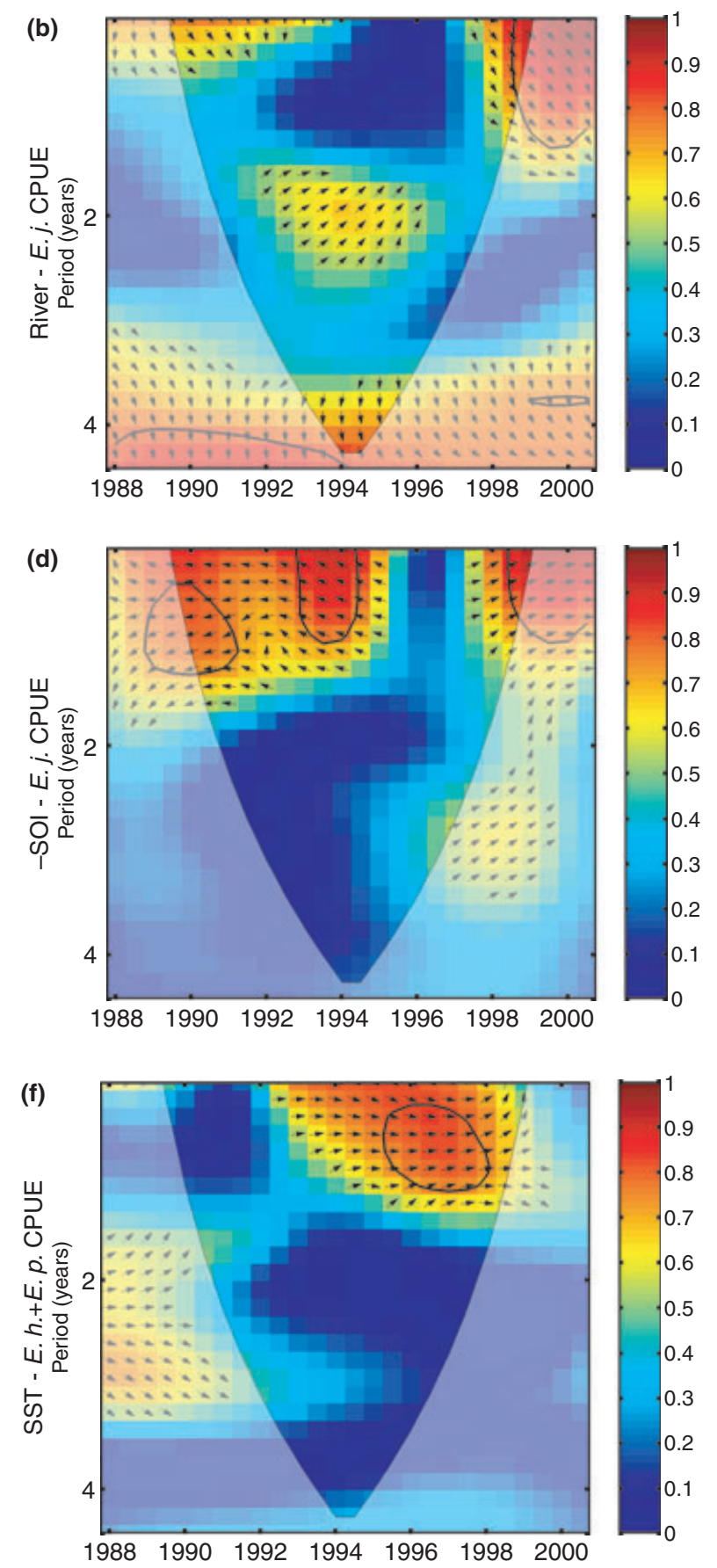

reduced the strength of the China Coastal Current (cf. Fig. 1) (Wu et al., 2007). We suspect that the reduced strength of the China Coastal Current decreased the fluxes of Japanese anchovy populations toward Taiwan.

(C) 2009 The Authors, Fish. Oceanogr., 18:2, 102-117. 
Figure 10. (Continued)
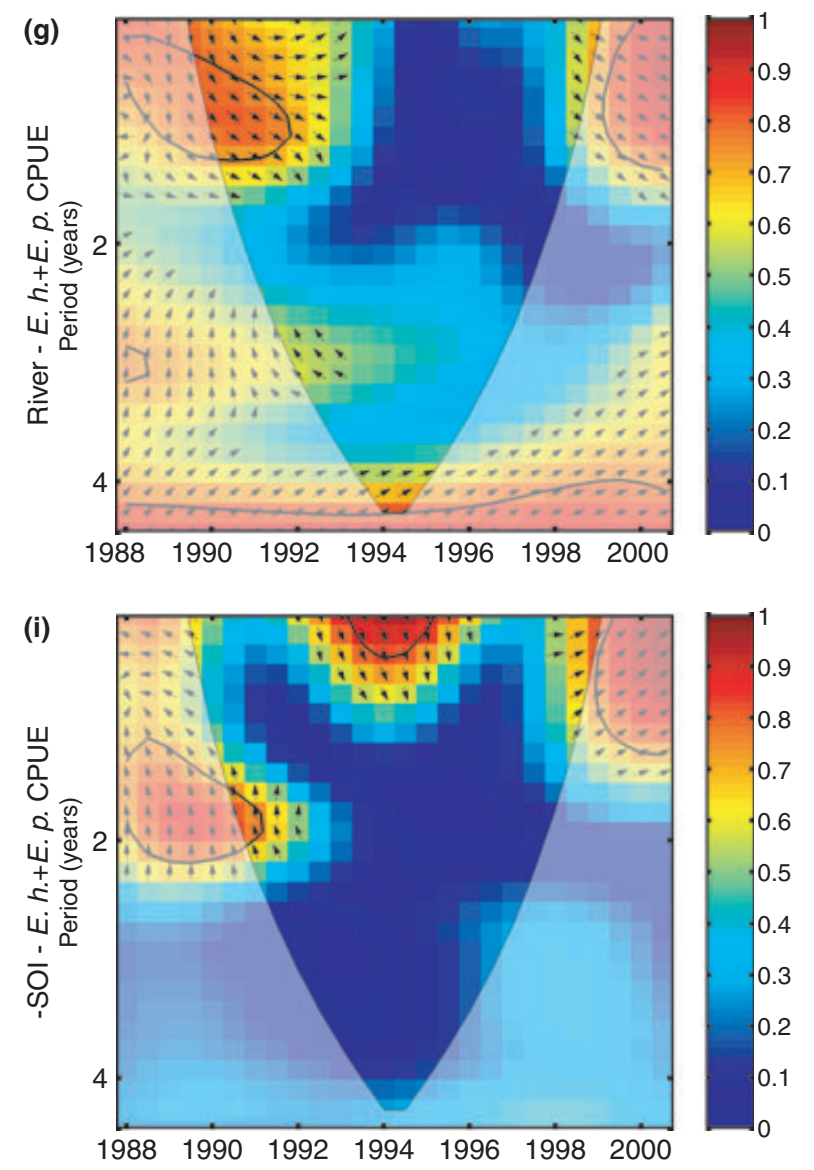

Our study was designed to investigate whether local environmental factors may have affected variations in the larval anchovy populations of southwestern Taiwan. We cannot provide unambiguous answers to this question based on our analyses; rather, we have identified two lines for future investigations. Firstly, the migration routes and the effects of ocean current fluxes into the Taiwan Strait require examination. Second, elucidating the environmental effects on larval survival in the spawning ground around Taiwan is necessary. Our results call for ecological studies of the anchovy population using fishery-independent data in the future. In addition to interannual fluctuations, the mechanisms underlying the stunning decline in anchovy populations should be scrutinized (Fig. 2). As fishing may reduce the resilience of exploited populations in responding climate change (Hsieh et al., 2006), fishing pressures and environmental changes might have synergistically precipitated such a decline. Furthermore, we suggest that advanced time series analyses such as those employed in the current study ought to be used more regularly and
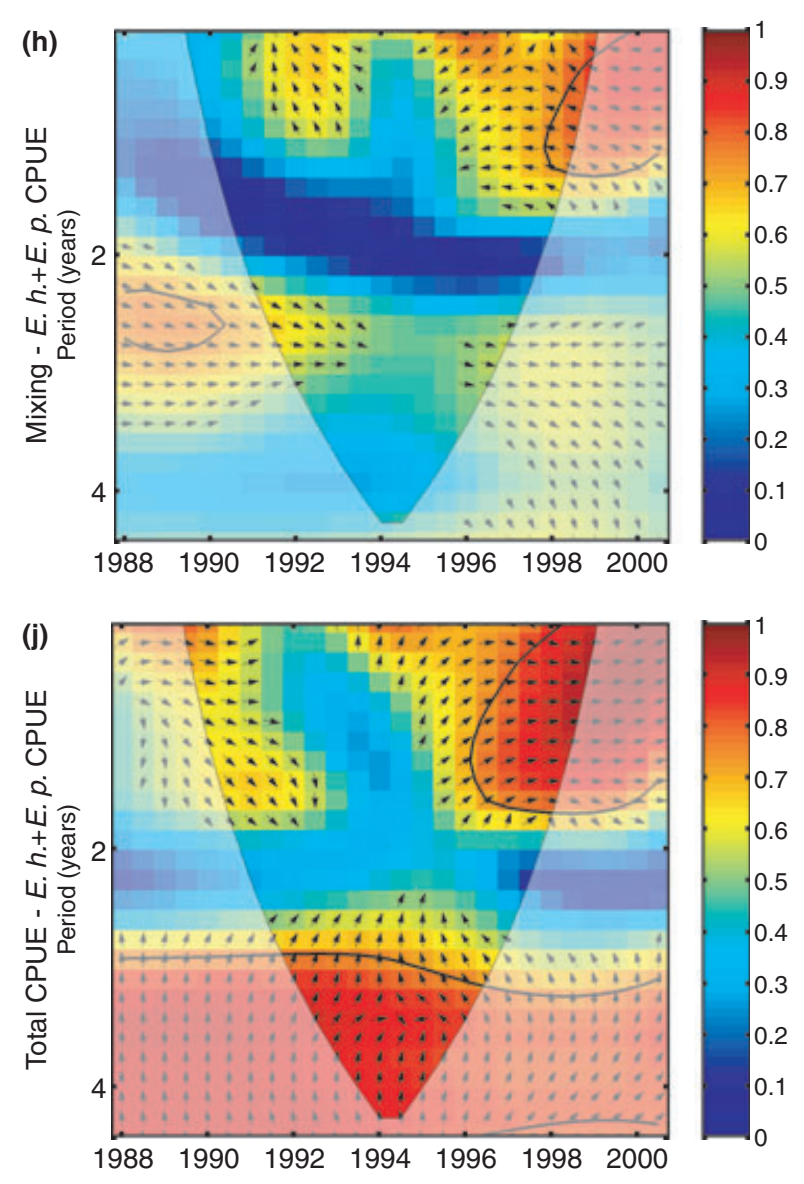

carefully to investigate environmental effects on biological populations.

\section{ACKNOWLEDGEMENTS}

Insightful comments by Gwo-Ching Gong and Changtai Shih improved our work. We thank Jaime Terceiro, José Manuel Casals, Miguel Jerez, Gregorio R. Serrano, and Sonia Sotoca for providing the MATLAB package, $E^{4}$ : State-space Estimation of Econometric ModELS. Our study was supported by National Science Council (NSC 96-2611-M-002-013-MY2), Taiwan Ocean Research Institute, the Council of Agriculture (92AS-9.1.1-FA-F1 and 97AS-15.1.1-FA-F1-6), and the Center for Marine Bioscience and Biotechnology, NTOU.

\section{REFERENCES}

Alheit, J. and Niquen, M. (2004) Regime shifts in the Humboldt Current ecosystem. Prog. Oceanogr. 60:201-222. 
Bakun, A. and Parrish, R.H. (1991) Comparative studies of coastal pelagic fish reproductive habitats - the anchovy (Engraulis anchoita) of the southwestern Atlantic. ICES J. Mar. Sci. 48:343-361.

Benson, A.J. and Trites, A.W. (2002) Ecological effects of regime shifts in the Bering Sea and eastern North Pacific Ocean. Fish Fish. 3:95-113.

Casals, J., Jerez, M. and Sotoca, S. (2002) An exact multivariate model-based structural decomposition. J. Am. Stat. Assoc. 97:553-564.

Chen, C.S. and Chiu, T.S. (2003) Early life history traits of Japanese anchovy in the northeastern waters of Taiwan, with reference to larval transport. Zool. Stud. 42:248-257.

Chiu, T.S. and Chen, C.S. (2001) Growth and temporal variation of two Japanese anchovy cohorts during their recruitment to the East China Sea. Fish. Res. 53:1-15.

Chiu, T.S., Young, S.S. and Chen, C.S. (1997) Monthly variation of larval anchovy fishery in I-lan Bay, NE Taiwan, with an evaluation for optimal fishing season. J. Fish. Soc. Taiwan 24:273-282.

Durbin, J. and Koopman, S.J. (2001) Time Series Analysis by State Space Methods. Oxford: Oxford University Press.

Efron, B. and Tibshirani, R. (1986) Bootstrap methods for standard errors, confidence intervals, and other measures of statistical accuracy. Stat. Sci. 1:54-75.

Fiedler, P.C., Methot, R.D. and Hewitt, R.P. (1986) Effects of California El Nino 1982-1984 on the northern anchovy. J. Mar. Res. 44:317-338.

Findley, D.F., Monsell, B.C., Bell, W.R., Otto, M.C. and Chen, B.C. (1998) New capabilities and methods of the X-12ARIMA seasonal adjustment program. J. Bus. Econ. Stat. 16:127-176.

Grinsted, A., Moore, J.C. and Jevrejeva, S. (2004) Application of the cross wavelet transform and wavelet coherence to geophysical time series. Nonlin. Processes Geophys. 11:561-566.

Hsia, K.Y., Lee, K.T. and Lee, M.A. (1998) Fishing ground formation of larval anchovy in relation to oceanography and meteorological conditions in the I-Lan Bay of northeastern Taiwan. J. Fish. Soc. Taiwan 25:239-249.

Hsia, K.Y., Lee, K.T., Liao, C.H. and Wang, J.E. (2004) Effects of changes in sea surface temperature on fluctuation in larval anchovy resources in coastal waters of aiwan. J. Fish. Soc. Taiwan 31:127-140.

Hsieh, C.H., Glaser, S.M., Lucas, A.J. and Sugihara, G. (2005) Distinguishing random environmental fluctuations from ecological catastrophes for the North Pacific Ocean. Nature 435:336-340.

Hsieh, C.H., Reiss, C.S., Hunter, J.R., Beddington, J.R., May, R.M. and Sugihara, G. (2006) Fishing elevates variability in the abundance of exploited species. Nature 443:859-862.

Hsieh, C.H., Anderson, C. and Sugihara, G. (2008) Extending nonlinear analysis to short ecological time series. Am. Nat. $171: 71-80$.

Ives, A.R. and Zhu, J. (2006) Statistics for correlated data: phylogenies, space, and time. Ecol. Appl. 16:20-32.

Jacobson, L.D., De Oliveira, J.A.A., Barange, M. et al. (2001) Surplus production, variability, and climate change in the great sardine and anchovy fisheries. Can. J. Fish. Aquat. Sci. 58:1891-1903.

Jan, S., Wang, J., Chern, C.S. and Chao, S.Y. (2002) Seasonal variation of the circulation in the Taiwan Strait. J. Mar. Syst. 35:249-268.
Jhun, J.G. and Lee, E.J. (2004) A new Asian winter monsoon index and associated characteristics of the winter monsoon. J. Climate 17:711-726.

Lee, H.-J. and Chao, S.-Y. (2003) A climatological description of circulation in and around the East China Sea. Deep Sea Res. Part II 50:1065-1084.

Lee, M.A. and Lee, K.T. (1996) The larval anchovy (Engraulis japonicus) fishery in relation to the environmental factors in coastal waters of Fangliao, Taiwan. Fish. Res. 26:37-48.

Lee, M.A., Lee, K.T. and Shiah, G.Y. (1995) Environmental factors associated with the formation of larval anchovy fishing grounds in the coastal waters of southwest Taiwan. Mar. Biol. 121:621-625.

Little, R.J.A. and Rubin, D.B. (2002) Statistical Analysis with Missing Data. New York: John Wiley \& Sons, Inc.

Lloret, J., Palomera, I., Salat, J. and Sole, I. (2004) Impact of freshwater input and wind on landings of anchovy (Engraulis encrasicolus) and sardine (Sardina pilchardus) in shelf waters surrounding the Ebre (Ebro) River delta (north-western Mediterranean). Fish. Oceanogr. 13:102-110.

Mantua, N.J., Hare, S.R., Zhang, Y., Wallace, J.M. and Francis, R.C. (1997) A Pacific interdecadal climate oscillation with impacts on salmon production. Bull. Am. Meterol. Soc. 78:1069-1079.

Maraun, D. and Kurths, J. (2004) Cross wavelet analysis: significance testing and pitfalls. Nonlin. Processes Geophys. 11:505-514.

Menard, F., Marsac, F., Bellier, E. and Cazelles, B. (2007) Climatic oscillations and tuna catch rates in the Indian Ocean: a wavelet approach to time series analysis. Fish. Oceanogr. 16:95-104.

Pikitch, E.K., Santora, C., Babcock, E.A. et al. (2004) Ecosystem-based fishery management. Science 305:346-347.

Politis, D.N. and Romano, J.P. (1994) The stationary bootstrap. J. Am. Stat. Assoc. 89:1303-1313.

Politis, D.N. and White, H. (2004) Automatic block-length selection for the dependent bootstrap. Econom. Rev. 23: 53-71.

Pyper, B.J. and Peterman, R.M. (1998) Comparison of methods to account for autocorrelation in correlation analyses of fish data. Can. J. Fish. Aquat. Sci. 55:2127-2140.

Takasuka, A., Oozeki, Y. and Aoki, I. (2007) Optimal growth temperature hypothesis: why do anchovy flourish and sardine collapse or vice versa under the same ocean regime? Can. J. Fish. Aquat. Sci. 64:768-776.

Torrence, C. and Compo, G.P. (1998) A practical guide to wavelet analysis. Bull. Am. Meterol. Soc. 79:61-78.

Torrence, C. and Webster, P.J. (1999) Interdecal changes in the ENSO-Monsoon system. J. Climate 12:2679-2690.

Trenberth, K.E. (1984) Signal versus noise in the Southern Oscillation. Mon. Weather Rev. 112:326-332.

Tsai, C.F., Chen, P.Y., Chen, C.P., Lee, M.A., Shiah, G.Y. and Lee, K.T. (1997) Fluctuation in abundance of larval anchovy and environmental conditions in coastal waters off southwestern Taiwan as associated with the El Niño-Southern Oscillation. Fish. Oceanogr. 6:238-249.

Wang, Y.T. and Tzeng, W.N. (1999) Differences in growth rates among cohorts of Encrasicholina punctifer and Engraulis japonicus larvae in the coastal waters off Tanshui River Estuary, Taiwan, as indicated by otolith microstructure analysis. J. Fish Biol. 54:1002-1016. 
Wroblewski, J.S. and Richman, J.G. (1987) The non-linear response of plankton to wind mixing events - implications for survival of larval northern anchovy. J. Plankton Res. 9:103-123.

Wu, C.-R., Chao, S.-Y. and Hsu, C. (2007) Transient, seasonal and interannual variability of the Taiwan Strait current. J. Oceanogr. 63:821-833.
Yu, H.T., Lee, Y.J., Huang, S.W. and Chiu, T.S. (2002) Genetic analysis of the populations of Japanese anchovy (Engraulidae: Engraulis japonicus) using microsatellite DNA. Mar. Biotechnol. 4:471-479.

Zhu, C., Lee, W.S., Kang, H. and Park, C.K. (2005) A proper monsoon index for seasonal and interannual variations of the East Asian monsoon. Geophys. Res. Lett. 32:L02811. 